\title{
Los efectos de las reformas del mercado de gas natural en México sobre sus precios, ventas y comercio exterior ${ }^{1}$
}

\author{
The effects of natural gas market reforms in Mexico \\ on its prices, sales and foreign trade
}

\author{
Francisco Ortiz Arango*1, José Carlos Ramírez², Juan Rosellón ${ }^{1,3}$ \\ ${ }^{1}$ ECEE, Universidad Panamericana, México \\ ${ }^{2}$ Profesor-investigador del Departamento de Estudios Económicos de El Colegio de la Frontera Norte, México \\ ${ }^{3}$ Departamento de Economía del Centro de Investigación y Docencia Económicas, México \\ ${ }^{3}$ German Institute for Economic Research, Germany \\ ${ }^{3}$ Center for Energy Studies, Rice University, United States of America
}

Recibido el 6 de febrero de 2020; aceptado el 27 de agosto de 2020

Disponible en Internet el: 4 de septiembre de 2020

\section{Resumen}

El objetivo de este artículo es evaluar los cambios producidos por las reformas regulatorias en el mercado del gas natural mexicano entre 2009 y 2018. Para tal efecto se realizan diversas pruebas unitarias y de quiebres estructurales a las series de volúmenes y precios del gas natural que describen su comportamiento en los mercados nacionales e internacionales. Los resultados del análisis estadístico sostienen que todas las series experimentan cambios estructurales en tendencia e intercepto entre 2016 y 2017 y, por tanto, presentan raíz unitaria. Las consecuencias de estos comportamientos son relevantes porque los shocks introducidos en las series son permanentes y atribuibles a la puesta en operación de la reforma.

\footnotetext{
${ }^{1}$ Francisco Ortiz Arango agradece los recursos procedentes del Proyecto 278934 del Fondo Sectorial CONACYT-Secretaría de Energía-Hidrocarburos, para la realización de esta investigación

*Autor para correspondencia

Correo electrónico: fortizar@up.edu.mx (F. Ortiz Arango).

La revisión por pares es responsabilidad de la Universidad Nacional Autónoma de México.

http://dx.doi.org/10.22201/fca.24488410e.2021.2841

0186- 1042/@ 2019 Universidad Nacional Autónoma de México, Facultad de Contaduría y Administración. Este es un artículo Open Access bajo la licencia CC BY-NC-SA (https://creativecommons.org/licenses/by-nc-sa/4.0/)
} 
Código JEL: D21, D47, L50, L51, Q41

Palabras clave: Reforma regulatoria; Gas natural; Series de tiempo; Cambio estructural, México

\begin{abstract}
The objective of this article is to evaluate changes produced by regulatory reforms in the Mexican natural gas market between 2009 and 2018. For this purpose, various unit tests and structural breaks are carried out on the series of volumes and prices of natural gas that describe their behavior in national and international markets. The results of the statistical analysis support that all series are subject to structural changes in tendency and intercept between 2016 and 2017, so that they show a unit root. Consequences of such behaviors are relevant the since shocks on series are permanent and due to the start of the reform.
\end{abstract}

JEL Code: D21, D47, L50, L51, Q41

Keywords: Regulatory reform; Natural gas; Time series analysis; Structural change, Mexico

\title{
Introducción
}

Con objeto de desarrollar un mercado robusto en el sector del gas natural en México, el gobierno ha emprendido dos reformas regulatorias en 1995 y 2013. A diferencia de otras experiencias internacionales, estas reformas han enfrentado desde el inicio las limitaciones políticas y jurídicas propias de la regulación de un mercado dominado por las empresas paraestatales: Petróleos Mexicanos (PEMEX), en el sector de hidrocarburos, y Comisión Federal de Electricidad (CFE), en la industria eléctrica.

Como se sabe, PEMEX mantenía antes de la primera reforma el monopolio de todas las fases de la producción de hidrocarburos. La empresa funcionaba, entonces, como propietario, operador y regulador del mercado nacional. Esta posición monopólica lo llevó a privilegiar los productos más rentables de su cartera de producción, en este caso petróleo crudo, y a relegar a otros, como el gas natural. La falta de inversión en el sector de gas natural que, estratégicamente, se consideraba de menor importancia que el crudo era explicado, en parte, por la existencia de combustóleo que, en ese entonces, representaba el principal sustituto del gas natural para el consumo industrial. Pero, si bien esta última fuente de energía era más barata que el gas natural, resultaba muy contaminante por su alto contenido de azufre. La creciente necesidad por fuentes de energía más limpias incrementó de tal suerte la demanda por gas natural hacia principios de los años 90 del siglo pasado (9\% anual2) que hubo necesidad de

\footnotetext{
${ }^{2}$ La tasa de crecimiento prevista en 1995 para la demanda de gas natural fue del $42 \%$ de 1997 a 1999 , y del 10\% anual del 2000 a 2007.
} 
introducir cambios en la regulación de los precios, aranceles y permisos para atraer la inversión privada en las actividades de distribución, almacenamiento y comercialización del producto.

Concretamente en 1992 se dieron los primeros pasos para la reforma del sector energético, cuando se permitió la inversión privada en la generación de energía. En octubre de 1993 se creó la Comisión Reguladora de Energía (CRE) dentro de la Secretaría de Energía, para regular el sector eléctrico únicamente en proyectos de autoconsumo, cogeneración y energía independiente que requerían vender sus excedentes de generación a la CFE. Dos años más tarde, la reforma del mercado del gas natural abrió el mercado a la participación privada. La liberalización de este mercado fue especialmente compleja, ya que combinaba monopolios naturales con actividades potencialmente competitivas. La producción se protegió como monopolio, a pesar de que la competencia era posible desde el punto de vista técnico. La transmisión y la distribución de gas se mantuvieron como monopolios naturales y la comercialización del gas fue reconocida como un mercado disputable.

Esta reforma formó parte de los cambios suscitados por la crisis económica de la década de los años ochenta, que obligó a algunos sectores, como los de infraestructura, a emprender transformaciones importantes que fomentaran el crecimiento económico. Las transformaciones incluyeron un plan de desregulación destinado a eliminar las barreras artificiales de entrada y salida en mercados disputables como el transporte, los puertos y telecomunicaciones, la privatización de las empresas estatales, incluida la compañía telefónica Telmex, y la apertura a la inversión privada en el sector del gas natural. ${ }^{3}$

Años más tarde, la reforma del 2013 profundizó sustancialmente la liberalización del sector de gas natural, al iniciar un ambicioso programa orientado a enfrentar la creciente demanda del producto en un escenario de baja producción de petróleo, altos costos de generación eléctrica, rezagos en la producción de energías renovables y perdidas no técnicas en la distribución y transmisión eléctricas. La magnitud de esta reforma resultó, por mucho, de mayor alcance que la de 1995 porque abarcó a casi todas las actividades en las que estaba involucrada el sector: petróleo crudo, petrolíferos y electricidad. Su promulgación requirió cambios en tres artículos constitucionales (25, 27 y 28), veintiún artículos transitorios, nueve nuevas leyes que regulaban la actividad de las paraestatales (es decir, la ley de Hidrocarburos, ley PEMEX, ley CFE, ley de la industria eléctrica), así como la reformulación de doce leyes adicionales. ${ }^{4}$ Las disposiciones promovieron la desintegración vertical de PEMEX y CFE y la creación de la figura de entidades productivas del estado, que permitieron establecer con-

\footnotetext{
${ }^{3}$ Un debate detallado sobre la desregulación del sector del gas natural es Rosellón (1998). Una referencia interesante relacionada con el proceso de privatización es Rogozinski (1999).

${ }^{4}$ Véase Ramírez and Massa (2020)
} 
tratos y asociaciones conjuntas con empresas privadas nacionales y extranjeras en diferentes campos de la actividad energética del país.

Los resultados acumulados de ambas reformas no siempre resultan de fácil medición, aunque no por eso dejan de ser impresionantes. Para efectos de ilustración conviene señalar, por ejemplo, que de los 11,347 km de gasoductos que existían en 2012, la red de transporte de gas se incrementó a 16,758 km para septiembre de 2019, con 2,131km más en construcción ${ }^{5}$. Como parte de esta expansión, se concedieron permisos a empresas privadas para operar la red con una celeridad nunca antes vista, pues ya para junio de 2017 estaban vigentes 566 permisos: 461 en operación y 105 en espera $^{6}$. Varios de estos permisos de gasoductos de transmisión se otorgaron para suministrar gas a las nuevas plantas independientes de generación de energía eléctrica.

Pero no obstante los avances logrados, queda claro que hay muchos problemas relacionados con la producción y suministro del gas natural en el país. Con respecto a la producción, ésta ha venido cayendo desde 2010 debido, principalmente, a la pobre inversión en exploración y perforación 7 . El país cuenta actualmente, según datos de enero de 2018, con apenas 10.022 billones de pies cúbicos de reservas probadas de gas natural, que arroja una relación reserva-producción de 5.4 años (Franco, 2019). Su volumen depende de la extracción de petróleo en el sureste del país y la zona offshore, donde se ventea alrededor del 10\% al 15\% del total de gas extraído. Para subsanar la demanda nacional insatisfecha, el país importa de los EEUU alrededor del $85 \%$ del gas consumido con un costo aproximado de 11,700 millones de dólares en 2017. ${ }^{8}$ Esta dependencia es un riesgo no solo por las consabidas razones geopolíticas, sino porque puede afectar el suministro a precios razonables de un producto que atraviesa la matriz energética del país. En 2017 el gas natural representó el 39.25\% del consumo total de energía primaria en México (BP, 2019), de cuyo total Pemex consumió el 7.1\%, mientras que el resto se destinó para la industria (33.5\%), la generación de electricidad (31.2\%) y el uso comercial y residencial (28.2\%).

El objetivo de este artículo es evaluar los impactos derivados del proceso de reforma del mercado de gas natural, iniciado en 1995 y culminado en 2013, sobre sus precios, valores y

\footnotetext{
${ }_{5}^{5}$ Reporte: Estatus de la infraestructura de Gas Natural. Octubre 2019. Secretaría de Energía. Págs. 4. https://www. gob.mx/cms/uploads/attachment/file/497827/Estatus_de_gasoductos_octubre_2019.pdf, consultado el 9 de junio de 2020.

${ }^{6}$ Reporte: Número de permisos y registros por sector, por actividad y por modalidad. Comisión Reguladora de Energía. Junio de 2017. https://datos.gob.mx/busca/dataset/numero-de-permisos-y-registros-por-sector-por-actividad-y-por-modalidad consultado el 12 de agosto de 2019.

${ }^{7}$ De acuerdo a la tabla Producción, reservas y capacidad de refinación de hidrocarburos en países seleccionados (1a parte). Sistema de Información Energética, Secretaría de Energía. http://sie.energia.gob.mx/movil.do?action=back\&node $=$ PMXB2C03.

${ }^{8}$ Ramírez and Massa (2020).
} 
volúmenes de las ventas nacionales y del comercio exterior. Las técnicas estadísticas incluidas en la evaluación comprenden pruebas de contraste de estacionariedad y de quiebres estructurales (Andrews-Ploberger y Zivot-Andrews) para las distintas series entre 2009 y 2018. La idea es diferenciar las series de variables que son reactivas a los cambios de la regulación, y que modifican su tendencia, de aquellas que no lo son o que conservan su tendencia. La conclusión principal del documento es que todas las series experimentan quiebres en intercepto y tendencia que modifican permanentemente la dirección de las trayectorias entre 2016 y 2017.

El artículo está organizado en tres secciones adicionales. La sección 2 presenta los aspectos esenciales de las reformas de 1995 y 2013. La sección 3 analiza e interpreta el comportamiento de las series de precios totales reales, precios al sector eléctrico, precios a la industria y distribuidores, volumen de importaciones, valor y volumen de comercio exterior del mercado del gas natural mexicano. Finalmente, las conclusiones resumen los resultados $\mathrm{y}$ alcances principales del estudio.

\section{Reformas Energéticas de 1995 y 2013}

En 1995 se llevó a cabo una reforma relativamente ambiciosa en el sector del gas natural. Dicha reforma permitió la inversión privada en nuevos proyectos de transmisión, distribución y comercialización del gas natural, pero mantuvo el monopolio de PEMEX en la producción. La reforma también tuvo un alcance institucional al otorgar a la CRE las facultades de un organismo regulador independiente, que le permitió emitir los estatutos del nuevo diseño de este mercado mediante el Reglamento de Gas Natural. ${ }^{9}$

En 1995 se modificó el marco legal de la industria del gas natural con el fin de establecer los principios generales de su desarrollo. De este modo, el Reglamento de Gas Natural se convirtió en el marco regulatorio que especificaba la organización, operación y regulación de la industria en el largo plazo. Los actores más importantes del mercado en el sector eran los transportistas, operadores de instalaciones de almacenamiento, distribuidores, comercializadores, consumidores y PEMEX. Se crearon entonces incentivos para que las empresas privadas invirtieran bajo la regulación de la CRE. Mientras que la Secretaría de Energía se convirtió en el líder de política pública de los recursos energéticos de la nación, PEMEX se dedicó a operar las actividades en el sector, y la CRE se separó de la Secretaría de Energía para funcionar como un organismo independiente.

\footnotetext{
${ }^{9}$ La reforma de 1995 no fue una reforma constitucional. Véase Rosellón y Halpern (2001).
} 
En 2013 se puso en marcha una reforma constitucional del sector de hidrocarburos, incluyendo petróleo y gas, con la idea de incrementar sustancialmente la participación privada en todo el sector energético mexicano. Esta reforma profundizó la de 1995 al consolidar a la Comisión Nacional de Hidrocarburos $(\mathrm{CNH})$ y crear organismos reguladores adicionales: la Agencia de Seguridad, Energía y Ambiente (ASEA), y el Centro Nacional de Control de Gas Natural (CENAGAS). El objetivo de la reforma consistió en impulsar la complementariedad de funciones y responsabilidades entre las nuevas agencias públicas y la CRE para, así, establecer un marco legal adecuado, que fomentara el crecimiento del sector mediante la coordinación de todas las áreas de la industria. En particular, el CENAGAS pasó a ser el propietario del sistema de gasoductos de PEMEX (rompiendo la integración vertical en la industria del gas natural), así como la agencia encargada de llevar a cabo la operación independiente de dicho sistema. ${ }^{10}$

Las reformas de 1995 y 2013 no son, en realidad, partes de un mismo proceso político o institucional. Sin embargo, la reforma del 2013 se puede entender como una profundización de la de 1995, sobre todo en el ámbito institucional. A continuación, analizamos con más detalles cada una de ellas.

\section{Reforma Energética de 1995}

La Reforma Institucional de 1995 buscó, desde un inicio, que los tomadores de decisiones implementaran una política pública de desincorporación y acceso abierto de las redes de gasoductos de transmisión, distribución y almacenamiento de gas natural. En particular, se pretendió que los nuevos distribuidores privados permitieran el acceso abierto a sus redes de distribución (bypass comercial). Este espíritu de la Reforma intentaba garantizar condiciones competitivas en el suministro de bienes y servicios a lo largo de la industria del gas natural.

Una de las primeras acciones emprendidas por esta Reforma fue la creación del Reglamento de Gas Natural (o, simplemente, el Reglamento), mediante el cual se establecieron nuevas reglas de operación en el mercado de gas natural que, a la postre, abrieron las puertas a la participación privada. Con ese espíritu, el Reglamento buscó contrarrestar el papel dominante de PEMEX al permitir cierto grado de integración vertical de parte de otros participantes del mercado. Sin embargo, la integración vertical entre la transmisión y la distribución se restringía para los casos en los que el permiso de transmisión (distribución) resultaba necesario para un proyecto de distribución (transmisión). En términos de comercio internacional,

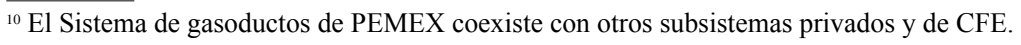


el Reglamento permitía las importaciones libres de gas natural procedentes de los Estados Unidos sin licencia o derechos de importación.

Los responsables de política pública se enfrentaron entonces al problema de decidir cómo regular el precio de ventas de primera mano y como llevar a cabo la distribución del gas natural. Después de considerar la experiencia internacional, eligieron la alternativa de fijar el precio de acuerdo con un punto de referencia internacional. Este punto de referencia estaba dado por el precio del gas natural en un mercado del suroeste de Estados Unidos (Houston Ship Channel o Henry $\mathrm{Hub}$ ), ajustado por el costo de transmisión y almacenamiento del gas en Ciudad Pemex, Tabasco. Un mecanismo similar había sido ya utilizado por PEMEX desde antes de la reforma de 1995, pero el Reglamento de 1995 desarrolló los detalles de este instrumento con miras de fomentar la competencia en el mercado mexicano. ${ }^{11}$

Por otra parte, existían barreras a la entrada en la construcción de redes de distribución de gas natural que, de acuerdo con el Reglamento, había que combatir para lograr un desarrollo armónico de los sistemas de distribución en México. Los reguladores decidieron, entonces, conceder periodos de exclusividad de 12 años a partir de la subasta inicial de una zona exclusiva de distribución de gas natural (franquicia). Sin embargo, la exclusividad de los distribuidores sólo se refería a la conducción del gas natural dentro de la zona. Los consumidores podían entonces efectuar gradualmente un bypass físico de la red del distribuidor, o un bypass comercial de dicha red de forma inmediata. ${ }^{12}$ Fiel a la práctica internacional de que las actividades de comercialización promueven la competencia a través del arbitraje de precios, los reguladores permitieron a los vendedores comprar gas, transportarlo y venderlo a distribuidores o a consumidores dentro de un área de exclusividad, y directamente conectados al sistema de transmisión.

Para obtener una franquicia de distribución de gas, los licitantes debían presentar un proyecto económico y técnico, luego la CRE elegía uno de ellos para la zona geográfica de distribución, definiendo el objetivo de consumo a cubrir al final de los primeros cinco años. La infraestructura de distribución que pertenecía a PEMEX y CFE en las zonas de distribución fue privatizada. Adicionalmente, con el fin de regular los precios monopólicos de los gasoductos de distribución y transmisión, los reguladores eligieron una combinación de dos instrumentos: regulación por costo del servicio y regulación por precio máximo. Al comienzo

\footnotetext{
${ }^{11}$ Un problema de esta metodología fue que los consumidores mexicanos podían ser afectados por externalidades del mercado estadounidense que podían implicar, en algunos casos, aumentos de las facturas de los consumidores mexicanos. Por ejemplo, los precios del gas natural sufrieron aumentos de más del 100\% en el invierno de 1996, y en el verano y otoño de 2000. Brito y Rosellón (2002) analizan las propiedades de eficiencia de esta metodología. ${ }^{12}$ Bypass o "puenteo" se refiere a la posibilidad de que un consumidor en una zona de distribución tiene de conectarse a la red de transmisión directamente (bypass físico) o de contratar la compra de gas natural de un proveedor distinto al distribuidor accediendo por acceso abierto a las redes de este último (bypass comercial).
} 
de cada quinquenio, se determinaba un precio máximo sobre la base del costo del servicio. Este precio máximo permanecería fijo durante el quinquenio y sólo sería ajustado por factores de inflación y eficiencia $(R P I-X)$. Asimismo, para regular la estructura de precios de la distribución de gas, México decidió utilizar dos variaciones del precio máximo: regulación por ingreso promedio en el primer período quinquenal, y regulación por canasta de tarifas en los siguientes quinquenios. ${ }^{13}$

El principal éxito de la reforma de 1995 fue el desarrollo de diversos sistemas de distribución de gas natural a lo largo del país. Para fines de la década de los 90’s, este proceso había logrado atraer más de 2 mil millones de dólares en inversión.

\section{Reforma Energética de 2013}

No obstante, los avances logrados con la Reforma de 1995, aún había temas nacionales e internacionales que requerían ser analizados dentro del contexto que vivía el sector energético. Por lo cual en 2013 se llevó a cabo una ambiciosa Reforma Constitucional del sector energético mexicano, que incluyó los mercados de petróleo, gas y electricidad. Esta reforma modificó por completo el marco institucional del sector. Hasta ese momento PEMEX era el inversor dominante del sector de hidrocarburos, pero esa creciente inversión no se reflejaba en incrementos de producción, ni en reservas de hidrocarburos. La falta de recursos técnicos y económicos por parte de PEMEX para explotar reservas en yacimientos no convencionales y en aguas profundas, imposibilitaba a la paraestatal de aprovechar el $76 \%$ de los recursos prospectivos de la nación que se encontraban en esos sitios. De ahí que la reforma del 2013 buscó establecer un marco regulatorio para complementar las inversiones de PEMEX con tecnologías de punta en la explotación de reservas en aguas profundas y ultra profundas, así como en campos maduros y yacimientos no convencionales.

Fue así, que el 20 de diciembre de 2013 se publicó en el Diario Oficial de la Federación, el "Decreto por el que se reforman y adicionan diversas disposiciones de la Constitución Política de los Estados Unidos Mexicanos, en Materia de Energía” (Reforma Energética), en el cual se reforman los párrafos cuarto, sexto y octavo del artículo 25; el párrafo sexto del artículo 27; los párrafos cuarto y sexto del artículo 28; y se adicionan un párrafo séptimo, al artículo 27 y el párrafo octavo al artículo $28^{14}$.

\footnotetext{
${ }^{13}$ Para un análisis detallado de los impactos de esta metodología en el excedente de consumo, véase Ramírez y Rosellón (2002).

${ }^{14}$ Decreto por el que se reforman y adicionan diversas disposiciones de la Constitución Política de los Estados Unidos Mexicanos, en Materia de Energía. Diario Oficial de la Federación 20 de diciembre de 2013.
} 
Para complementar el desarrollo del marco jurídico requerido para iniciar la operación efectiva de esta Reforma, se enunciaron los artículos cuarto y décimo transitorios de este Decreto, en los cuales se estableció un plazo de ciento veinte días para que el Congreso de la Unión realizara las adecuaciones al marco jurídico que resulten necesarias, a fin de hacer efectivas las disposiciones del Decreto, entre ellas, regular las modalidades de contratación, que deberán ser, entre otras: de servicios, de utilidad o producción compartida, o de licencia, para llevar a cabo, por cuenta de la Nación, las actividades de exploración y extracción del petróleo y de los hidrocarburos sólidos, líquidos o gaseosos, incluyendo las que pudieran realizar las empresas productivas del Estado con particulares, así como las adecuaciones necesarias para establecer las atribuciones de la Secretaría de Energía, la Comisión Nacional de Hidrocarburos y la Comisión Reguladora de Energía ${ }^{15}$.

En cumplimiento a lo dispuesto en los artículos cuarto y décimo transitorios citados, el 30 de abril de 2014, el Ejecutivo Federal envió al Senado de la Republica la iniciativa de leyes secundarias a la reforma constitucional aprobada en diciembre de 2013. El Senado revisó, modificó y aprobó las propuestas y esto dio lugar a que el paquete de leyes secundarias en materia energética se publicara en el Diario Oficial de la Federación el 11 de agosto de 2014. En ellas se destaca la creación de nuevos instrumentos jurídicos con el objetivo de instrumentar el nuevo diseño institucional del sector Hidrocarburos: La Ley de Hidrocarburos y la Ley de los Órganos Reguladores Coordinados en Materia Energética, entre otras, que otorgan una nueva naturaleza jurídica y nuevas atribuciones y responsabilidades para la Comisión Nacional de Hidrocarburos (CNH) y la Comisión Reguladora de Energía (CRE), así como la creación de un nuevo ente regulador, en forma de órgano desconcentrado de la Secretaría del Medio Ambiente y Recursos Naturales: la Agencia de Seguridad, Energía y Ambiente (ASEA), la cual obedecía a la importancia que reviste la seguridad industrial y protección al medio ambiente en la reforma energética aprobada. La ASEA tiene entre sus funciones principales regular la seguridad industrial de las instalaciones petroleras y de gas, y expedir regulaciones de protección ambiental. En particular, PEMEX, las empresas privadas e, incluso CENAGAS deben acatar las disposiciones de la ASEA.

La tabla 1 presenta un resumen de la legislación secundaria publicada en el Diario Oficial de la Federación el 11 de agosto de 2014, en el que se expidieron 9 nuevas leyes y se reformaron 12 leyes existentes ${ }^{16}$,

\footnotetext{
15 Ídem.

${ }^{16}$ Decreto por el que se expide la Ley de Ingresos sobre Hidrocarburos, reforman, adicionan y derogan diversas disposiciones de la Ley Federal de Derechos y de la Ley de Coordinación Fiscal y se expide la Ley del Fondo Mexicano del Petróleo pata la Estabilización y el Desarrollo. Diario Oficial de la Federación 11 de agosto de 2014.
} 
Tabla 1

Cambios en la Legislación secundaría del Sector Energético. DOF 11/08/2014

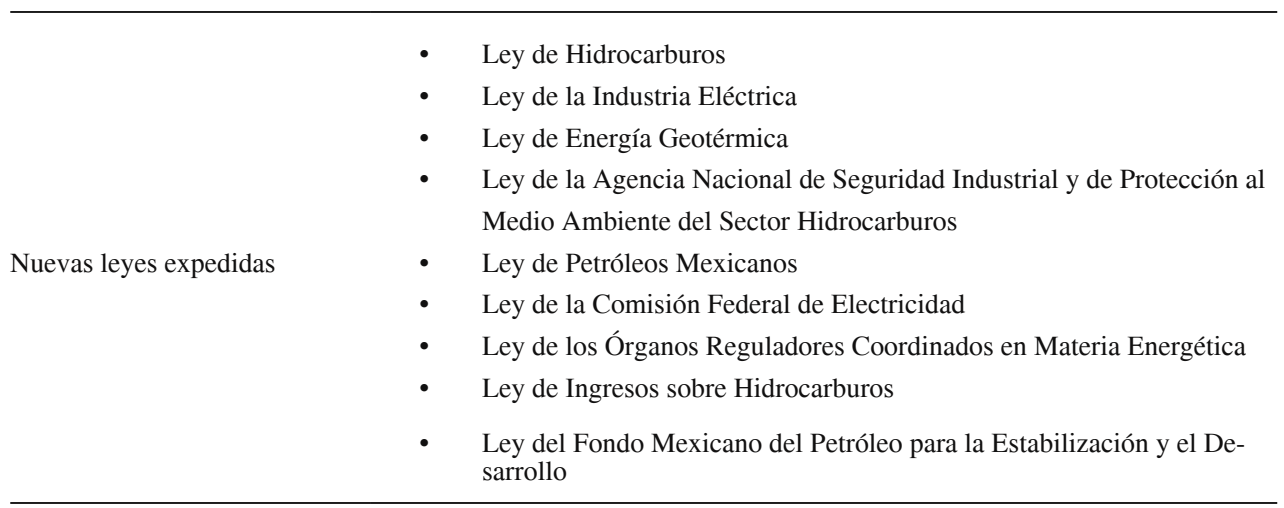

- $\quad$ Ley de Inversión Extranjera

- Ley Minera

- Ley de Asociaciones Público-Privadas

- Ley de Aguas Nacionales

- $\quad$ Ley Federal de las Entidades Paraestatales

Leyes reformadas

- Ley de Adquisiciones, Arrendamientos y Servicios del Sector Público

- Ley de Obras Públicas y Servicios Relacionados con las Mismas

- Ley Orgánica de la Administración Pública Federal

- Ley Federal de Derechos

- Ley de Coordinación Fiscal

- Ley Federal de Presupuesto y Responsabilidad Hacendaria

- $\quad$ Ley General de Deuda Pública

Cabe mencionar que, en materia eléctrica, la Reforma Energética creó el Centro Nacional de Control de Energía (CENACE) como operador independiente para implementar el Mercado Eléctrico Nacional y, convirtió, además, a la CFE en Empresa Productiva del Estado, lo que permitió la asociación entre CFE y privados en generación, transmisión y distribución de electricidad.

Condensando los cambios en materia de Hidrocarburos de la Reforma Energética de 2013:

- Reafirmó la propiedad nacional de los hidrocarburos en el subsuelo

- Permitió la apertura a la participación de privados en actividades de Exploración y Extracción de Hidrocarburos a través de Contratos de Exploración y Extracción de Hidrocarburos con el Estado 
- Fortaleció a los órganos reguladores: Comisión Reguladora de Energía (CRE) y Comisión Nacional de Hidrocarburos (CNH)

- Estableció un nuevo régimen fiscal para PEMEX y compañías privadas

- Convirtió a Pemex en Empresa Productiva del Estado

- Reorganizó la estructura personal y administrativa de PEMEX para incrementar su productividad y autorizó los farmouts ${ }^{17}$ para la extracción de petróleo

- Creó el Fondo Mexicano del Petróleo para la Estabilización y el Desarrollo

- Fortaleció a los órganos reguladores CRE y CNH

- La CNH organizó varias rondas de subastas para la explotación y producción de campos petroleros

Debemos destacar la creación del CENAGAS como organismo público descentralizado. Con base en la Reforma, el CENAGAS se convirtió en el operador independiente del sistema de gasoductos, además de propietario de alrededor de 9,000 km de ductos. Su función tiene dos objetivos fundamentales: Primero, maximizar el bienestar social, en su función de operador de los sistemas de ductos (que incluyen los de propiedad privada y los de CFE) y, por otro lado, el de maximizar los beneficios de administrar sus ductos propios. La creación de CENAGAS puede verse asimismo como uno de los principales resultados de la reforma del 2013, ya que permitió romper la integración vertical de PEMEX en la industria del gas natural, favoreció la competitividad a lo largo de la cadena de esta industria, e incrementó la capacidad de los gasoductos en el país de 11,347 km en 2012 a 15,986 km en junio de 2018. En septiembre de 2019 entraron en operación 772 km más y están en construcción otros 2,131 km, con lo cual se llegará próximamente a 18,889 km de gasoductos (SENER, 2019).

Como se puede ver la reforma del 2013 buscó incrementar la producción petrolera, la capacidad de las redes de gasoductos, y expandir asimismo la capacidad de transporte y almacenamiento del petróleo y de combustibles líquidos. Además, con base en estas nuevas condiciones legales y operativas, se lograría alcanzar inversiones de alrededor de 50 mil millones de dólares en el sector energético de hidrocarburos de México, entre otros objetivos (Pérez y Zubicaray 2017, pág. 6).

\footnotetext{
${ }^{17}$ Son asociaciones entre empresas del sector público y privado que permiten a una empresa pública, en este caso PEMEX, compartir riesgos financieros, tecnológicos y geológicos con una compañía privada para estabilizar su producción petrolera e incrementarla gradualmente.
} 


\section{Análisis y resultados sobre precios, ventas y comercio exterior en el mercado del gas natural mexicano: efectos de la reforma}

\section{Base de datos y metodología}

Los datos utilizados provienen del Sistema de Información Energética de la Secretaría de Energía de México con información de PEMEX y comprenden las variables más importantes del comercio exterior y las ventas nacionales de gas natural entre enero del 2009 y diciembre del 2018. Las series mensuales sobre valores y cantidades de las ventas nacionales incluyen las transacciones totales y su división por sectores (industrial-distribuidoras y eléctrico), mientras que las del comercio exterior aparecen desplegadas en volúmenes y valores del saldo neto de la balanza comercial. Inicialmente las series datan de 1993 pero, por omisiones en el registro de varias variables durante largos periodos de tiempo, no es posible disponer de información regular y confiable sino hasta el mes de septiembre de 2005. En nuestro caso tomamos como punto de partida el mes de enero de 2009 no solo porque su elección permite tener una muestra balanceada hacia atrás (2009-2013) y hacia adelante (2014-2018) del periodo de observación de la reforma energética del 2013 sino, principalmente, porque se trata del año en que la producción nacional de gas alcanza su pico más alto con 7 mil millones de pies cúbicos. Es decir, tomamos un inicio de periodo excepcional para observar el movimiento de las variables asociado con la caída sistemática de la producción local de gas. El tamaño de la muestra resultante es, pues, de 120 observaciones para cada una de las series.

Para obtener los precios promedios reales del gas por metro cubico, en forma agregada y por sectores industrial y eléctrico, dividimos el valor de las transacciones mensuales en dólares constantes del 2015 por las cantidades respectivas en metros cúbicos. Del mismo modo, y con el fin de hacer comparaciones en el tiempo, transformamos los valores de pesos corrientes del saldo de la balanza comercial en dólares constantes de ese año. De esta manera, las series originales quedan re-expresadas en precios constantes, valores deflactados con los índices de precios al consumidor de EEUU y cantidades de gas en metros cúbicos.

Una vez hecho esto, analizamos la dinámica de cada serie mediante dos procedimientos sucesivos y complementarios. El primero estudia el comportamiento de sus primeras diferencias con base en la prueba de Kwiatkowski-Phillips-Schmidt-Shin (KPSS), cuya Hipótesis Nula $\left(\mathrm{H}_{0}\right)$ establece que las series de tiempo reales son estacionarias en torno a una tendencia determinista (Kwiatkowski, 1992). La idea es determinar su proceso estocástico subyacente $\mathrm{y}$, en caso de que presente reversión a la media, calcular el tiempo de regreso promedio a la tendencia de cada serie después de experimentar un shock. Para tal efecto utilizamos la 
medida escalar de persistencia llamada vida media del $\operatorname{shock}^{18}$ (VMS), que está ligada a las funciones de impulso-respuesta de cada ecuación auto-regresiva:

$$
V M S=A B S\left(\frac{\ln 0.5}{\ln \alpha}\right)
$$

donde $\alpha$ es el estimador insesgado de la media del coeficiente autoregresivo de orden 1 .

El segundo paso analiza los posibles cambios estructurales de los niveles de las series con base en las pruebas de Andrews (1993), Andrews y Ploberger (1994) y Zivot y Andrews (1992). Como se sabe, la adopción de determinados modelos de series de tiempo y sus correspondientes tipos de pruebas para estimar los cambios estructurales no deja de ser un asunto controversial. Y es que hay tal diversidad de modelos que su elección requiere de una justificación empírica. Tenemos, por ejemplo, modelos diseñados para capturar cambios extremos (outliers) o modelos que incorporan cambios con parámetros continuos. Asimismo, hay modelos con regresiones que aceptan cambios repentinos de régimen y otros que, por el contrario, buscan estimar cambios graduales. En cada caso las pruebas son diferentes pues dependen de si: (a) los puntos de quiebre son conocidos o desconocidos; (b) los quiebres son individuales o múltiples; (c) las relaciones entre variables son univariadas o multivariadas; o (d) las variables son estacionarias o no estacionarias (Maddala and Kim, 1998).

Paralelo a este problema de elección se agrega el hecho de que pruebas como la KPSS o la aumentada de Dickey-Fuller (ADF) no son robustas ante la existencia de cambios o quiebres en las series. La presencia de quiebres en series que son estacionarias puede incrementar el valor del estimador autoregresivo al extremo de no poder rechazar la hipótesis de raíz unitaria como sucede, por ejemplo, cuando se usa ADF (Perron, 1990). Por esta razón es importante armar una estrategia en el tratamiento estadístico que incluya, por un lado, pruebas de contraste de estacionariedad sin tendencia y, por otro lado, pruebas que capturen quiebres en series estacionarias o con raíz unitaria.

En el segundo procedimiento optamos por utilizar, primero, el estadístico de KPSS sin tendencia y, luego, los modelos y pruebas de quiebres en intercepto, tendencia e intercepto y tendencia, arriba mencionados. La razón es que los estadísticos que evalúan tendencia como el KPSS modificado requieren la fijación de un choque exógeno, lo cual contraviene los objetivos de las pruebas de Andrews (1993), Andrews y Ploberger (1994) y Zivot y Andrews (1992).

\footnotetext{
${ }^{18}$ De acuerdo a (Cheung and Lai, 2000), la vida media de una unidad de shock se define como la duración de tiempo que toma una unidad de impulso en disiparse a la mitad de intensidad del shock inicial.
} 
Los trabajos de estos autores estiman un quiebre desconocido (o endógeno) en rupturas secuenciales para modelos sin tendencia determinística o estocástica (Maddala and Kim, 1998).

Concretamente los trabajos de Andrews (1993) y Andrews y Ploberger (1994) proponen diferentes versiones de una misma prueba en la que $\mathrm{H}_{\mathrm{o}}$ establece que la serie no tiene cambio estructural. Ambos proveen los valores críticos asintóticos para diversos niveles de significancia de una prueba de razón de verosimilitud que considera una variación estructural con un punto de cambio desconocido (similar a la prueba de Quandt). Esos valores críticos son llamados los estadísticos SUP o pruebas de Chow (Maddala and Kim, 1998). En su versión más desarrollada, Andrews y Ploberger (1994) suponen que sí existe un cambio estructural en un tiempo desconocido, éste ocurre entre las observaciones $T_{1}$ y $T_{2}$, donde $T_{1}$ es una observación cercana a 1 y $T_{2}$ es una observación cercana a $T$ del periodo muestral $t \in[1, T]$ . Cuando el cambio acontece en un periodo de tiempo conocido, los autores recomiendan tomar el intervalo en cuestión para maximizar la potencia de la prueba.

El algoritmo de la prueba para $N$ divisiones entre las observaciones $T_{1}$ y $T_{2}$ requiere, primero, computar el valor de $\chi^{2}$ para la hipótesis de existencia de un cambio estructural en $T_{1}$. Esto implica hacer tres estimaciones para los periodos que van de 1 a $T_{1}-1$, de $T_{1}$ a $T$ y de 1 a $T$. A este valor se le denota como $\chi^{2(1)}$. Enseguida se repite el mismo procedimiento para la observación $T_{1}+1$ a fin de obtener $\chi^{2(2)}$. Para cuando se prueba la hipótesis en $T_{2}$, el procedimiento habrá arrojado $N=T_{2}-T_{1}+1$ valores de $\chi^{2}$, esto es: $\chi^{2(1)}, \chi^{2(2)}, \ldots, \chi^{2(N)}$. Con estos valores, los autores construyen un promedio ponderado (que no es más que el estadístico de prueba AP) para confrontarlo con los valores críticos de tabla y, así, establecer los criterios de rechazo o aceptación de $\mathrm{H}_{0}$. El estadístico AP se define como:

$$
A P=\log \left[\left(e^{\frac{1}{2} \chi^{2(1)}}+\ldots+e^{\frac{1}{2} \chi^{2(N)}}\right) / N\right] .
$$

La prueba de Zivot-Andrews (1992), por su parte, plantea como $\mathrm{H}_{0}$ la existencia de raíz unitaria con deriva y como hipótesis alternativa la presencia de procesos estacionarios con rupturas en tendencia. Es decir, constituye una prueba que acentúa los cambios estructurales en las series estacionarias y, a diferencia de las pruebas KPSS o ADF detecta raíces unitarias de manera robusta e independientemente de esos cambios. Como en la prueba de Andrews y Ploberger (1994), la de Zivot-Andrews modela la ruptura desconocida en forma secuencial ya sea en intercepto $(I)$, tendencia $(T e)$ o en ambas $(I-T e)$. El procedimiento consiste en estimar las ecuaciones $(I),(T e)$ y $(I-T e)$ por mínimos cuadrados en forma secuencial para los valores de $T_{B}=2, \ldots, T-1$ cuando hay $T$ observaciones. El punto de quiebre en cada uno de los 
tres modelos ocurre cuando uno de los valores de los estadísticos $t$ asociados al último rezago de $T_{B}$ alcanza su punto mínimo.

Las ecuaciones para los tres modelos son:

Modelo (1): $\quad Y_{t}=\beta_{0}+\theta D U+\tau Y_{t-1}+\beta_{1} t+\sum_{j=1}^{k} c_{j} \Delta Y_{t-j}+U_{t}$,

donde los términos de la derecha son respectivamente: el intercepto, la variable dicotómica que toma el valor de 1 o 0 después y antes del cambio estructural, la variable endógena rezagada, la tendencia lineal, los $j$ términos rezagados de las primeras diferencias de la variable endógena y el termino de error;

Modelo $(T e): \quad Y_{t}=\beta_{0}+\lambda D T_{t}+\tau Y_{t-1}+\beta_{1} t+\sum_{j=1}^{k} c_{j} \Delta Y_{t-j}+U_{t}$.

en el que el único cambio es la inclusión de la variable dicotómica $D T$, que captura el quiebre estructural en tendencia con valores de 0 y 1 para indicar los cambios antes y después de la ruptura; finalmente tenemos la ecuación del último modelo que no es más que la combinación lineal de los dos anteriores:

$$
\operatorname{Modelo}(\mathrm{I}-\mathrm{Te}) \quad Y_{t}=\beta_{0}+\theta D U+\lambda D T_{t}+\tau Y_{t-1}+\beta_{1} t+\sum_{j=1}^{k} c_{j} \Delta Y_{t-j}+U_{t}
$$

En resumen, usamos los dos procedimientos para combinar técnicas convencionales de contraste de estacionariedad con métodos robustos de quiebres estructurales para caracterizar de una forma más completa la dinámica de las series de precios y cantidades del gas natural en México. Ambos procedimientos ofrecen información complementaria y confirmatoria de la posible existencia de un probable y desconocido cambio estructural producido por la reforma energética. El estudio de los niveles y primeras diferencias de las series es, pues, un recurso necesario para usar adecuadamente los dos tipos de procedimientos. En lo que toca al estudio de los dos métodos aquí empleados para calcular los cambios estructurales, Maddala y Kim (1998) sostienen que los estimadores de sus parámetros tienen propiedades asintóticas deseables que los hacen eficientes e insesgados con relación al tamaño de la muestra.

Para los dos procedimientos estadísticos se utilizan las siguientes librerías programadas en lenguaje R: 
- library(dplyr). Hadley Wickham, Romain François, Lionel Henry and Kirill Müller (2019). dplyr: A Grammar of Data Manipulation. R package version 0.8.3. https:// CRAN.R-project.org/package $=$ dplyr

- library(tseries). Adrian Trapletti and Kurt Hornik(2018). tseries: Time Series Analysis and Computational Finance. $R$ package version 0.10-46.

- library(CPAT). Curtis Miller (2018). CPAT: Change Point Analysis Tests. R package version 0.1.0.https://CRAN.R-project.org/package $=C P A T$

- library(strucchange). Achim Zeileis, Christian Kleiber, Walter Kraemer and Kurt Hornik

- library(TSA). Kung-Sik Chan and Brian Ripley (2018). TSA: Time Series Analysis. $R$ package version 1.2. https://CRAN.R-project.org/package $=$ TSA

\section{Los resultados}

Los resultados del cuadro 1 muestran que, al considerar sus primeras diferencias, cinco de las seis series bajo estudio tienen tendencia estacionaria y solo una, la de comercio exterior medida en valores, sigue un proceso de raíz unitaria (ver columna de rechazo y aceptación de KPSS). Contrario a las series con raíces unitarias, las funciones de impulso-respuesta empleadas en las pruebas de las series estacionarias tienden a desvanecerse o, lo que es lo mismo, los shocks sobre las series de tiempo son absorbidos por la media de la tendencia. Concretamente, en algunos procesos autoregresivos asociados a cada una de ellas se puede observar que la vida media de una unidad de shock (VMS) es muy corta.

Para ver esto con más claridad consideremos, primero, la ecuación (1). De acuerdo con esta ecuación, los precios del sector eléctrico y el volumen de importaciones tardan entre 5 y 29 meses en que los shocks temporales sean absorbidos por la tendencia respectivamente, mientras que, en el caso de las series de comercio exterior en valores, los shocks son permanentes, porque hacen cambiar la tendencia. En las series restantes, el regreso a su media móvil (volumen de comercio exterior) o a su tendencia después de dos rezagos (precios-Industrial-distribuidoras) es indeterminado porque, al no ser procesos AR (1), éste no puede ser calculado mediante el VMS. De todos modos, la conclusión no cambia, ya que la mayoría de las series sigue una trayectoria marcada por su tendencia que, como se aprecia, en las figuras de la descomposición aditiva, difieren en comportamiento según se trate de precios cantidades o valores (ver las figuras 1) 
En los precios totales y del sector eléctrico y distribuidoras, las series presentan una tendencia parecida, dentro un rango determinado, sin mayores cambios que los observados entre 2011 y 2016, aunque con diferencias estacionales. Entre ellas destacan las representadas por los picos del uso del sistema eléctrico o de las distribuidoras en los periodos de abril-mayo y noviembre-diciembre. Las series de importación, valor y volumen del comercio exterior presentan, por su parte, cambios de tendencia, sin rango determinado, más acentuados que las series de precios alrededor de 2014 y 2016, con componentes estacionales en diciembre-febrero (importación de gas), mayo-junio (valor del comercio exterior) y junio-octubre (volumen y comercio exterior). Para apreciar mejor estos cambios, con y sin rango determinado, es conveniente comparar, por ejemplo, las series de precios totales con la del volumen total de importaciones. Mientras que los precios totales oscilan entre un rango de 0.08 y 0.18 con escasos picos que escapan de dicho rango en 2010, 2012 y 2016, el volumen importado no tiene rangos de oscilación de las series, con la excepción del periodo posterior a 2016.

Cuadro 1

Pruebas de raíz unitaria para las primeras diferencias $(\Delta)$ de las series de tiempo de gas de México y cálculo de VMS para el periodo comprendido entre enero de 2009 y diciembre de $2018{ }^{19}$

\begin{tabular}{|c|c|c|c|c|c|c|c|c|c|}
\hline \multirow{3}{*}{ SERIES } & \multirow{2}{*}{\multicolumn{2}{|c|}{ Prueba KPSS }} & \multirow{3}{*}{$\begin{array}{c}\text { Proceso } \\
\text { ARIMA }\end{array}$} & \multicolumn{5}{|c|}{ SERIES DE TIEMPO } & \multirow{3}{*}{$\begin{array}{c}\text { VMS } \\
\text { (meses) }\end{array}$} \\
\hline & & & & & COEFIC & ENTES & & \multirow{2}{*}{ Criterio BIC } & \\
\hline & Ho & $\mathrm{p}$-value & & $\mathrm{AR}(1)$ & $\operatorname{AR}(2)$ & $\operatorname{MA}(1)$ & Media & & \\
\hline$\Delta_{\text {Total }}$ & No Rechazo & 0.1 & {$[1,0,0]$} & $\begin{array}{c}0.8641 \\
(0.0460)\end{array}$ & & & $\begin{array}{c}0.1195 \\
(0.0085)\end{array}$ & -616.4 & 4.75 \\
\hline $\begin{array}{c}\Delta \text { Precios - } \\
\text { Sector Eléctrico }\end{array}$ & No Rechazo & 0.1 & $(1,0,0)$ & $\begin{array}{c}0.8722 \\
(0.0445)\end{array}$ & & & $\begin{array}{c}0.1179 \\
(0.0089)\end{array}$ & -619.63 & 5 \\
\hline $\begin{array}{c}\triangle \text { Precios - } \\
\text { Industrial } \\
\text { Distribuidoras }\end{array}$ & No Rechazo & 0.1 & $(2,0,0)$ & $\begin{array}{c}0.6430 \\
(0.0936)\end{array}$ & $\begin{array}{c}0.2152 \\
(0.0939)\end{array}$ & & $\begin{array}{c}0.123 \\
(0.009)\end{array}$ & -583.99 & \\
\hline$\underset{\substack{\text { Importación - } \\
\text { Volumen }}}{\Delta}$ & No Rechazo & 0.1 & $(1,0,0)$ & $\begin{array}{c}0.9766 \\
(0.0190)\end{array}$ & & & $\begin{array}{l}1118.82 \\
(351.66)\end{array}$ & 1333.47 & 29.3 \\
\hline $\begin{array}{l}\Delta \text { Comercio } \\
\text { exterior - } \\
\text { Volumen }\end{array}$ & No Rechazo & 0.1 & $(1,0,1)$ & $\begin{array}{c}0.9886 \\
(0.0152)\end{array}$ & & $\begin{array}{l}-0.1908 \\
(0.109)\end{array}$ & $\begin{array}{l}-1105.3 \\
(424.9)\end{array}$ & 1356.4 & \\
\hline $\begin{array}{c}\Delta \text { Comercio } \\
\text { exterior - Valor }\end{array}$ & Rechazo & 0.01 & NA & & CESO CON & Aíz UNITA & & & $\infty$ \\
\hline
\end{tabular}

Nota: Los números entre paréntesis en la columna de coeficientes son los errores estándar.

Fuente: Sistema de Información Energética, con información de Petróleos Mexicanos. http://sie.energia.gob.mx/ movil.do?action=back\&node $=$ PMXB2C03

\footnotetext{
${ }^{19}$ Nota: Tanto en las figuras como en el cuadro 1, en todos los casos en que se consideren precios, estos están expresados como "rendimientos", donde, donde son los precios en el tiempo t y son los precios del tiempo base. Cuando el valor de VMS no aparece, significa que la serie no regresa a su tendencia durante el periodo considerado.
} 
Descomposición aditiva de Precio_total

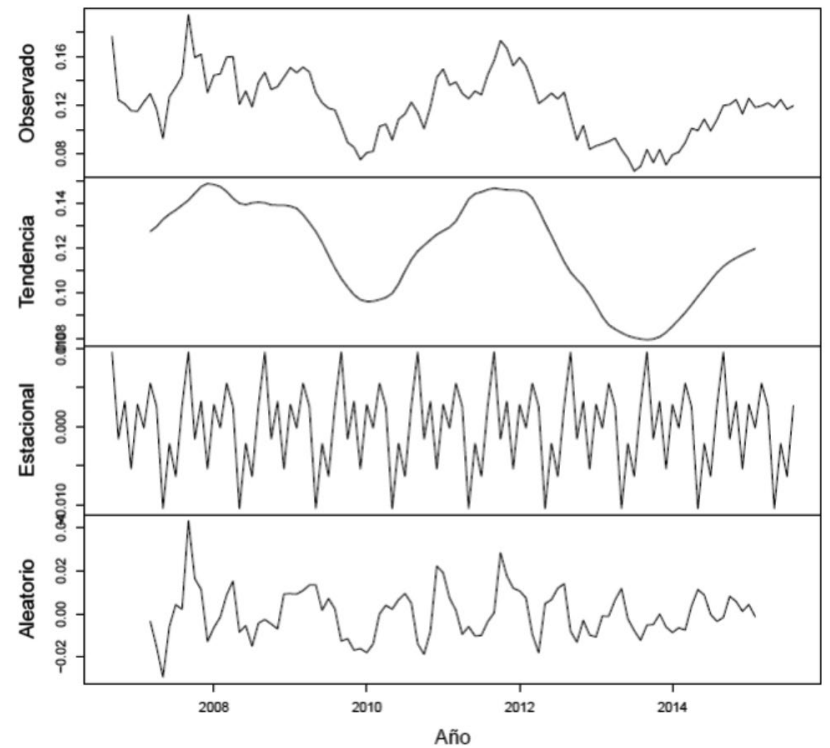

Figura 1(a). Descomposición aditiva de la serie de Precio Total de gas natural.

Descomposición aditiva de Precio_Industrial_distribuidoras

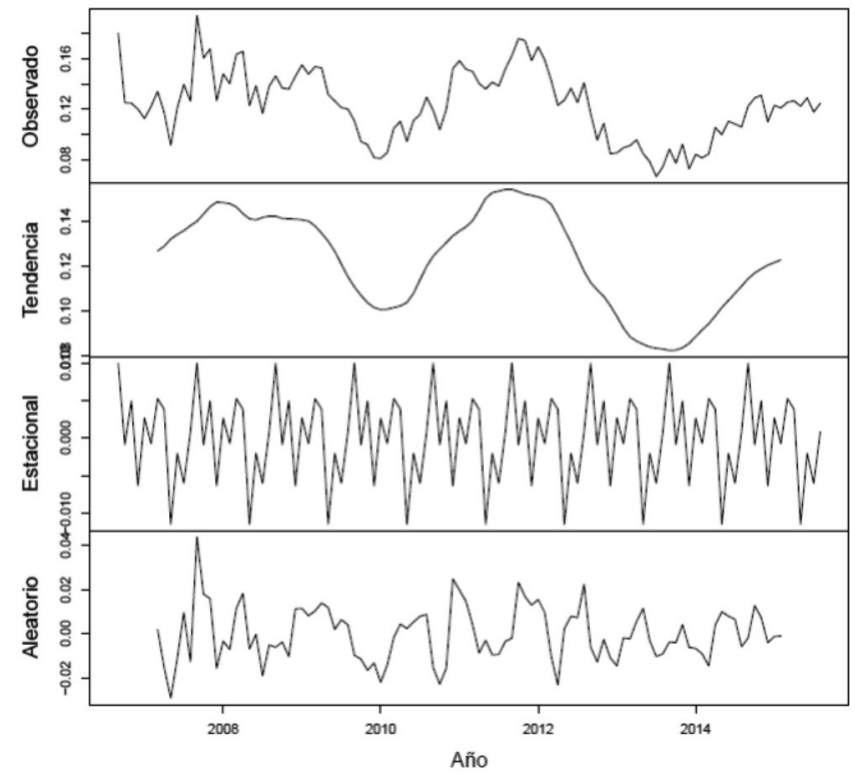

Figura 1(b). Descomposición aditiva de la serie de Precio de gas natural a la industria y distribuidoras. 
Descomposición aditiva de Precio_S_electrico

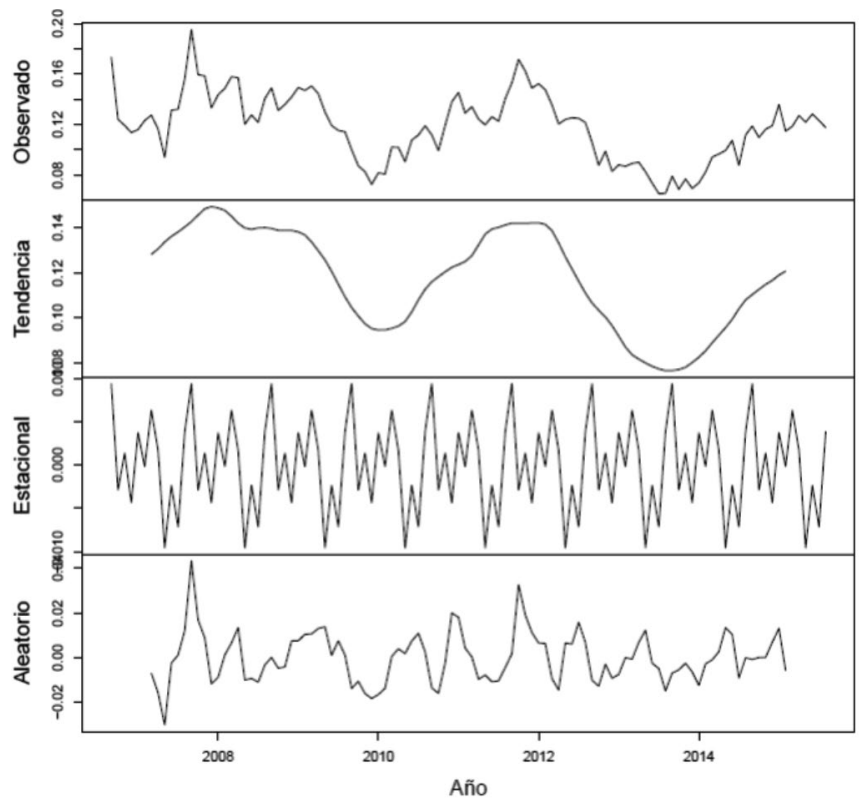

Figura 1(c). Descomposición aditiva de la serie de precio de gas natural al sector eléctrico.

Descomposición aditiva de Vol_Importacion_gas

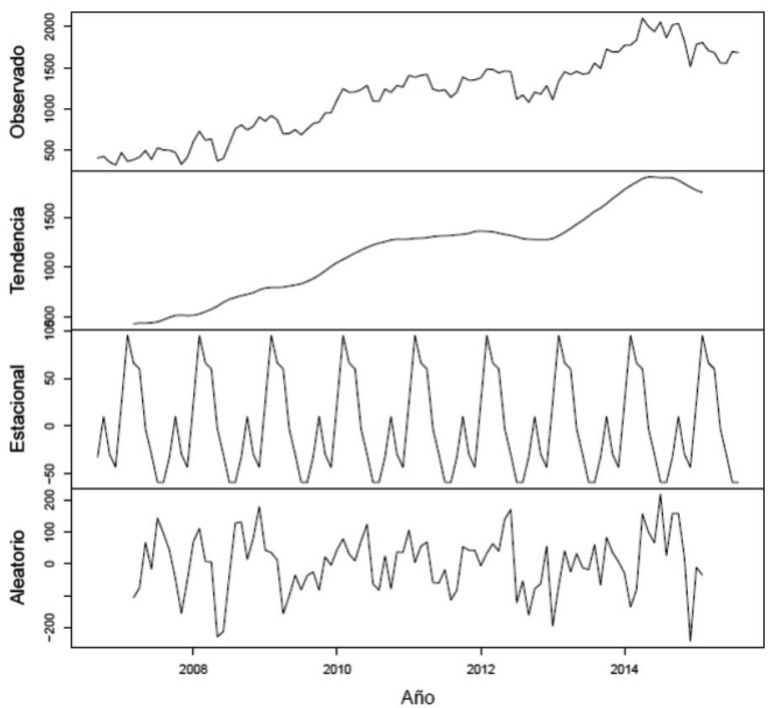

Figura 1(d). Descomposición aditiva de la serie del volumen de importación de gas natural 


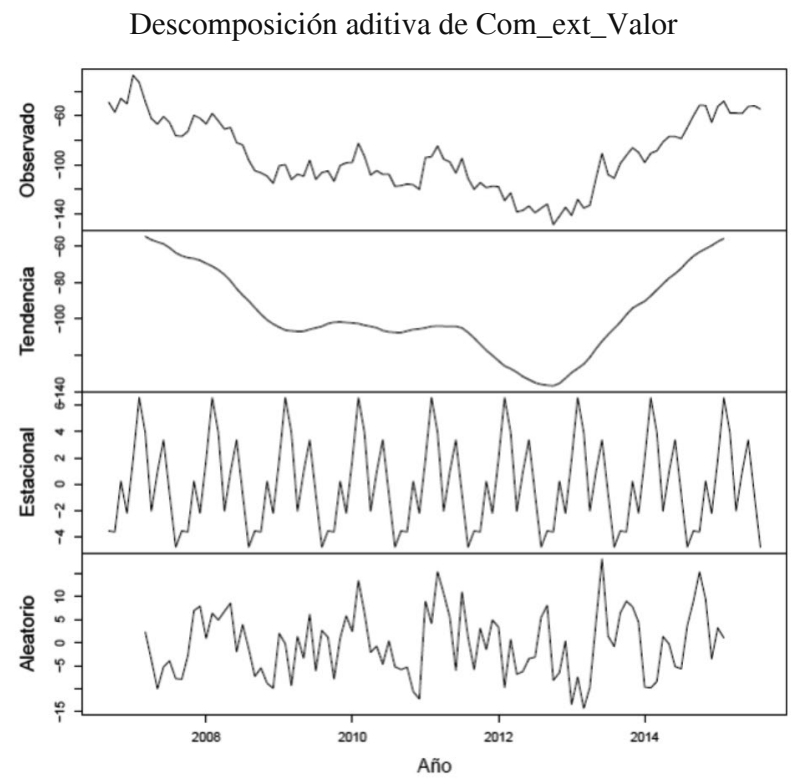

Figura 1(e). Descomposición aditiva de la serie del valor del comercio exterior de gas natural.

Descomposición aditiva de Com_ext_Vol

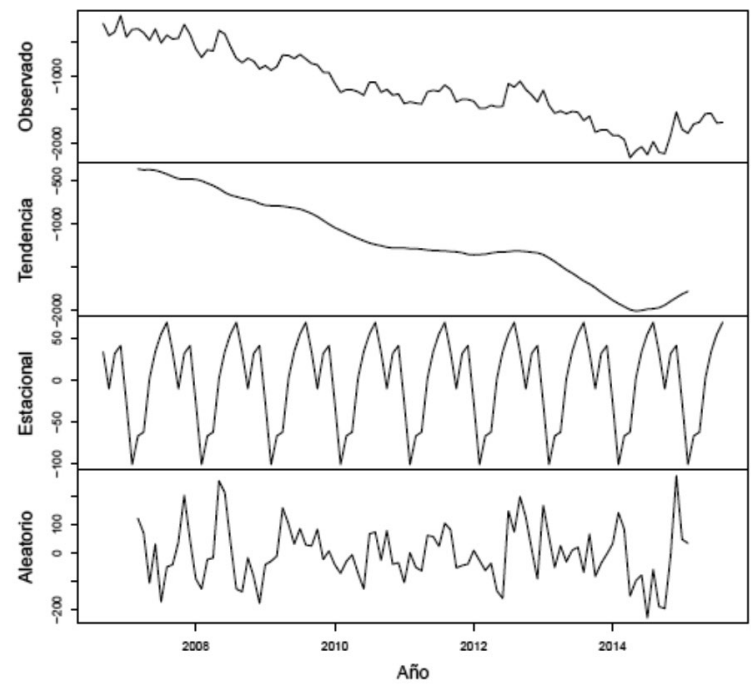

Figura 1(f). Descomposición aditiva de la serie del volumen del comercio exterior de gas natural. 
El punto interesante en el análisis es determinar si este comportamiento de las series se altera con la presencia de cambios estructurales. Puesto en términos de pregunta: ¿es posible confiar en el cálculo tradicional de estacionariedad para asegurar que cualquier shock en las cinco series estacionarias producido, por ejemplo, por la reforma energética es temporal? Para responder la pregunta, necesitamos antes hacer las pruebas sobre los niveles de las series, ya que las ecuaciones (2), (3), (4) y (5) son modelos que, de entrada, ajustan los datos para diferentes rezagos, por lo que, si incorporamos las series del cuadro 1, los ajustes involucrarían rezagos sobre primeras diferencias. Las pruebas de quiebres ya mencionadas no aceptan estimaciones de series con tendencias como las incluidas en dicha tabla.

La Tabla 2 reporta los resultados del estadístico KPSS con sus respectivos valores $p$. Ahí se muestra que todas las variables presentan raíz unitaria, como es común en la mayoría de las series económicas expresadas en niveles ¿Es este comportamiento una señal de inconsistencia con los resultados de la Tabla 1? La revisión de las pruebas de Andrews y Ploberger (1993) y Zivot y Andrews (1994) para intercepto, tendencia e intercepto y tendencia ofrece información al respecto. De acuerdo con la parte izquierda de la Tabla 3 (prueba de Andrews Ploberger) todas las series presentan quiebres estructurales en el periodo comprendido entre 2009 y 2018. En particular, cinco series experimentan quiebres en tendencia e intercepto en 2016 (agosto y diciembre) y solo una en 2015 (enero), es decir en el periodo posterior a la reforma energética. De esas series, las relativas al volumen de comercio exterior y al precio total registraron primero un quiebre en tendencia (2016) y luego en intercepto (en 2017), lo cual indica que los shocks resultaron más súbitos en esas variables que en las restantes. Estos resultados son, en buena medida, confirmados con la prueba de Zivot y Andrews ya que, con excepción de algunas diferencias pequeñas en las fechas, se observa el mismo patrón en la parte derecha de la Tabla 3. El significado de este patrón es que todas las series exhiben cambios estructurales permanentes en tendencia e intercepto en los años de operación de la reforma $(2014,2016$ y 2017) que permiten caracterizar a las series con raíz unitaria.

De esta manera, las respuestas a las dos preguntas que formulamos arriba es directa: en ausencia de quiebres estructurales, los criterios de estacionariedad tradicionales para las series de gas en México son dudosos cuando no se rechaza $\mathrm{H}_{0}$, porque no permiten detectar la naturaleza de los shocks. Un shock en una serie originalmente estacionaria que afecta su tendencia puede alterar por siempre el regreso a su media y, por tanto, hacer inútil el uso de indicadores como el VMS. De aquí que las pruebas sobre series en primeras diferencias de la Tabla 1 en las que no rechaza $\mathrm{H}_{0}$ están bajo sospecha porque subestiman el impacto de los cambios estructurales. No solo el significado de estacionariedad es diferente, sino que cambia, 
también, el sentido de la especificación, pues con shocks que favorecen la presencia de raíz unitaria no es aconsejable asociarle el mismo modelo de una serie de tiempo antes y después del cambio estructural. En este sentido los procesos ARIMA descritos en la tabla 1 tienen una validez limitada porque no se sabe en qué medida son afectados por los cambios estructurales.

Tabla 2

Pruebas de KPSS para las series de gas (en niveles) en México entre 2009 y 2018

\begin{tabular}{|c|c|c|}
\hline Variable & Conclusión & KPSS \\
\hline $\begin{array}{l}\text { Volumen de importaciones de gas natural } \\
\text { (millones de metros cúbicos diarios) }\end{array}$ & Raíz unitaria & $0.20(0.017)$ \\
\hline $\begin{array}{l}\text { Comercio Exterior de Gas Natural } \\
\text { (millones de metros cúbicos) }\end{array}$ & Raíz Unitaria & $0.19(0.028)$ \\
\hline $\begin{array}{l}\text { Comercio Exterior de Gas Natural } \\
\text { (millones de dólares) }\end{array}$ & Raíz unitaria & $0.18(0.036)$ \\
\hline $\begin{array}{l}\text { Precio Total de Gas Natural } \\
\text { (dólares/ metro cubico diario) }\end{array}$ & Raíz unitaria & $0.62(0.031)$ \\
\hline $\begin{array}{l}\text { Precio Servicio industrial-distribuidoras } \\
\text { (dólares/metro cúbico) }\end{array}$ & Raíz Unitaria & $0.56(0.045)$ \\
\hline $\begin{array}{c}\text { Precio Servicio eléctrico } \\
\text { (dólares/metro cúbico diario) }\end{array}$ & Raíz Unitaria & $0.61(0.033)$ \\
\hline
\end{tabular}

Nota. Al lado del estadístico de prueba se presenta el valor $p$ entre paréntesis.

Fuente: Sistema de Información Energética, con información de Petróleos Mexicanos. http://sie.energia.gob.mx/ movil.do?action=back\&node=PMXB2C03

La intuición económica de los resultados de la Tabla 3 es que los precios, valores y cantidades de gas natural tienden a ser inflexibles a la baja o al alza después de que sus series experimentan quiebres en tendencia e intercepto. En las figuras 2 podemos observar que, mientras una serie tiende persistentemente a la baja en octubre de 2016 (volumen de importaciones), las restantes tienden al alza en los distintos meses de 2016 y 2017. Esos quiebres en dirección vienen asociados con cambios en el nivel o en la media de la tendencia (debido a los cambios en el intercepto) 
Las consecuencias de estos comportamientos para la reforma energética son importantes porque, los efectos de los shocks son permanentes y atribuibles a su periodo de operación. Las causas de esos cambios son de origen local e internacional. En particular las alzas ocurridas en los precios totales del gas después del quiebre de 2016 son persistentes porque son fijados en mercados internacionales, en el que el gobierno mexicano actúa como precio-aceptante. Sin embargo, esto no quiere decir que, en ausencia de cambios estructurales, estos precios no hayan presentado en algunos años reversión a la media con algunos quiebres estructurales en intercepto, como sucedió por ejemplo entre 2007 y 2011 (Hu et al. 2019).

Las series de volúmenes o los precios del servicio eléctrico e industrial son, en cambio, más volátiles debido a que dependen fuertemente de las variaciones de la demanda interna y de la errática producción local. Concretamente, los volúmenes de importación de gas natural de EE UU aumentaron a una razón de 2.4 veces entre 2014 y 2017 tras la culminación del proyecto del gasoducto de los Ramones, al pasar de 728,692 millones de pies cúbicos en el primer año a 1,712,627 millones de pies cúbicos en el último año (Ramírez y Massa 2020). No obstante que a partir de 2017 esas cifras de importación empezaron a disminuir, estas todavía representan aproximadamente el $65 \%$ del consumo nacional, lo que equivale a una compra diaria de 4,800 millones de pies cúbicos que implican una erogación superior a 12 millones de dólares (Russo, 2017).

En este sentido podemos concluir que los efectos recientes de la reforma energética son duraderos porque revierten la tendencia. Pero hay que tener en mente que hay otros cambios no capturados por la prueba de Zivot-Andrews que pueden revelar otras conductas. Como dijimos en el anterior apartado, esta prueba registra el punto de quiebre donde los valores de los estadísticos $t$ asociados al último rezago de $T_{B}$ alcanzan su punto mínimo entre 2009 y 2018. Esto quiere decir que si subdividimos el intervalo en periodos previos y posteriores a los grandes quiebres estructurales, es posible que encontremos comportamientos estacionarios asociados con procesos con reversión a la media, como los descritos en la Tabla 1. Sin embargo, este tipo de ejercicios escapa de los alcances del objetivo de este documento. 
F. Ortiz Arango, et al. / Contaduría y Administración 66(3), 2021, 1-31

http://dx.doi.org/10.22201/fca.24488410e.2021.2841

Tabla 3

Pruebas de Andrews-Ploberger y Zivot-Andrews

\begin{tabular}{|c|c|c|c|c|c|c|}
\hline \multirow{3}{*}{$\begin{array}{c}\text { Variable } \\
\text { Volumen de importa- } \\
\text { ciones de gas natural } \\
\text { (millones de metros }\end{array}$} & \multicolumn{3}{|c|}{ Andrews-Ploberger } & \multicolumn{3}{|c|}{ Zivot-Andrews } \\
\hline & Intercepto & Pendiente & Ambos & Intercepto & Pendiente & Ambos \\
\hline & 06/2012 & $08 / 2016$ & $08 / 2016$ & $11 / 2012$ & $10 / 2016$ & $10 / 2016$ \\
\hline cúbicos diarios) & $(43.65)[0.009]$ & $(17.52)[0.000]$ & $(46.67)[0.000]$ & $(-3.42)[0.217]$ & $(-4.43)[0.059]$ & $(-4.78)[0.097]$ \\
\hline \multirow{3}{*}{$\begin{array}{l}\text { Comercio Exterior de } \\
\text { Gas Natural (volumen } \\
\text { en millones de metros } \\
\text { cúbicos diarios) }\end{array}$} & Intercepto & Pendiente & Ambos & Intercepto & Pendiente & Ambos \\
\hline & 07/2017 & 08/2016 & $08 / 2016$ & $06 / 2016$ & $01 / 2017$ & $01 / 2017$ \\
\hline & $(53.47)[0.000]$ & $(87.18)[0.000]$ & $(37.12)[0.000]$ & $(-3.37)[0.223]$ & $(-4.81)[0.069]$ & $(-5.24)[0.074]$ \\
\hline Comercio Exterior de & Intercepto & Pendiente & Ambos & Intercepto & Pendiente & Ambos \\
\hline \multirow{2}{*}{$\begin{array}{l}\text { Gas Natural (valor en } \\
\text { millones de dólares) }\end{array}$} & 03/2013 & $01 / 2015$ & $01 / 2015$ & $11 / 2013$ & $10 / 2014$ & $10 / 2014$ \\
\hline & $(67.92)[0.000]$ & $(76.65)[0.000]$ & $(76.65)[0.000]$ & $(-4.35)[0.114]$ & $(-4.41)[0.061]$ & $(-4.42)[0.137]$ \\
\hline \multirow{3}{*}{$\begin{array}{l}\text { Precio del gas natural } \\
\text { (dólares por metro } \\
\text { cúbico) }\end{array}$} & Intercepto & Pendiente & Ambos & Intercepto & Pendiente & Ambos \\
\hline & $01 / 2017$ & $11 / 2016$ & $11 / 2016$ & $06 / 2014$ & $04 / 2016$ & $04 / 2016$ \\
\hline & $(22.34)[0.000]$ & $(22.83)[0.000]$ & $(23.10)[0.000]$ & $(-4.17)[0.134]$ & $(-3.86)[0.119]$ & $(-4.68)[0.108]$ \\
\hline \multirow{3}{*}{$\begin{array}{l}\text { Servicio industrial-dis- } \\
\text { tribuidoras (dólares/ } \\
\text { metro cúbico diario) }\end{array}$} & Intercepto & Pendiente & Ambos & Intercepto & Pendiente & Ambos \\
\hline & $01 / 2015$ & $12 / 2016$ & $12 / 2016$ & $12 / 2014$ & $05 / 2016$ & $05 / 2016$ \\
\hline & $(31.27)[0.000]$ & $(14.58)[0.003]$ & $(15.21)[0.001]$ & $(-4.69)[0.077]$ & $(-4.14)[0.089]$ & $(-5.29)[0.068]$ \\
\hline \multirow{3}{*}{$\begin{array}{c}\text { Servicio eléctrico } \\
\text { (dólares/metro cúbico } \\
\text { diario) }\end{array}$} & Intercepto & Pendiente & Ambos & Intercepto & Pendiente & Ambos \\
\hline & $12 / 2014$ & $12 / 2016$ & $12 / 2016$ & 07/2014 & $04 / 2016$ & $04 / 2016$ \\
\hline & $(18.91)[0.000]$ & $(24.7)[0.005]$ & $(21.48)[0.008]$ & $(-3.79)[0.175]$ & $(-3.74)[0.133]$ & $(-4.42)[0.138]$ \\
\hline
\end{tabular}

Nota. Al lado del estadístico de prueba se presenta el valor p entre paréntesis. 
En las figuras siguientes, la línea continua representa los cambios estructurales de Zivot-Andrews y la línea discontinua los cambios estructurales según Andrews-Ploberger.

Volumen de importaciones de gas natural

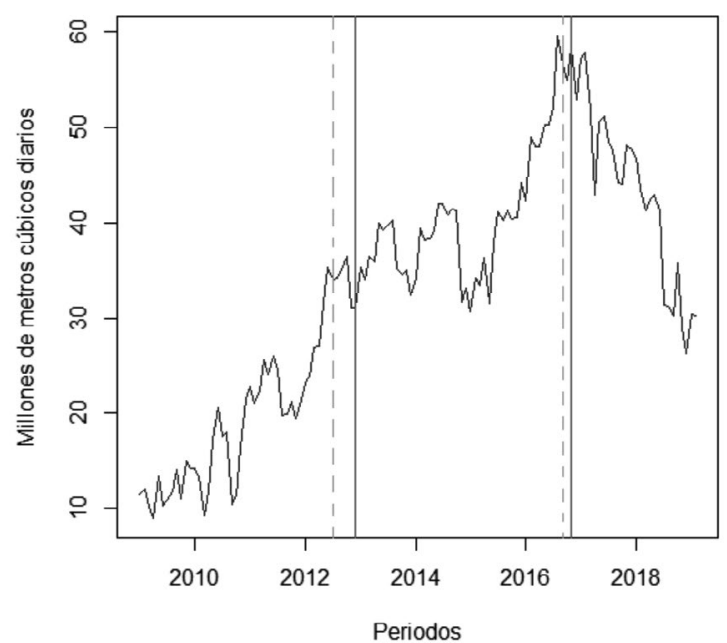

Figura 2(a). Puntos de cambios estructurales en la serie de volumen de importaciones de gas natural.

\section{Comercio Exterior de Gas Natural}

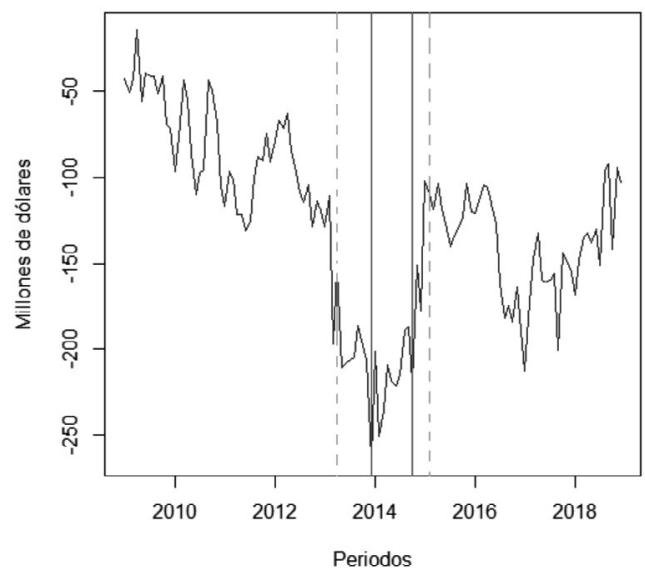

Figura 2(b). Puntos de cambios estructurales en la serie de comercio exterior en dólares de gas natural. 
F. Ortiz Arango, et al. / Contaduría y Administración 66(3), 2021, 1-31

http://dx.doi.org/10.22201/fca.24488410e.2021.2841

Comercio Exterior de Gas Natural

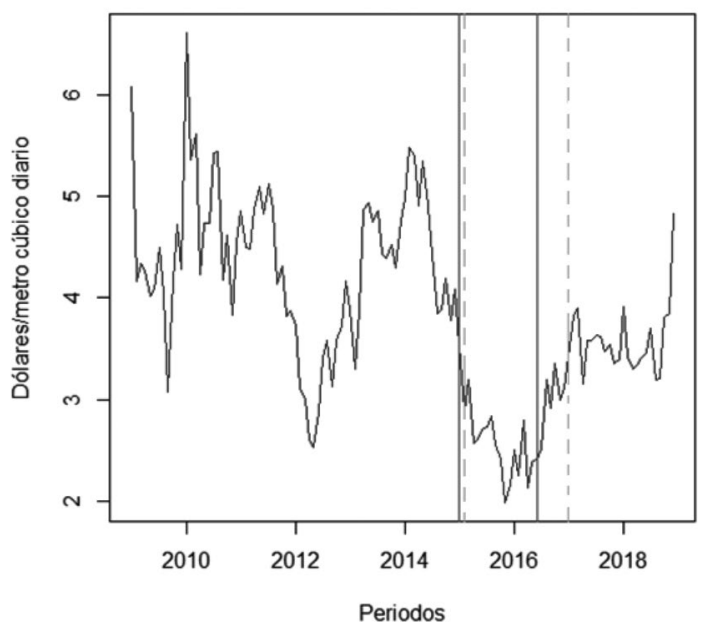

Figura 2(c). Puntos de cambios estructurales en la serie de comercio exterior en volumen de gas natural.

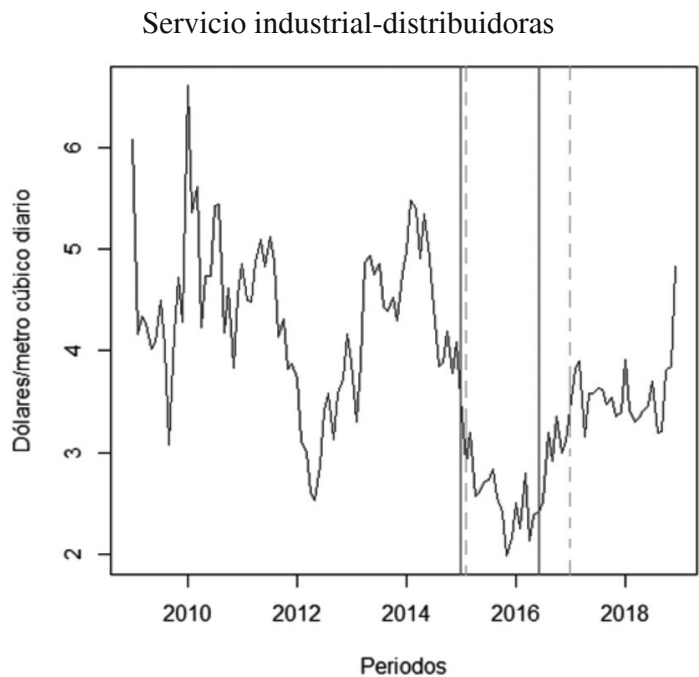

Figura 2(d). Puntos de cambios estructurales en la serie de gas natural utilizado en servicios industriales y distribuidoras. 
Servicio electrico

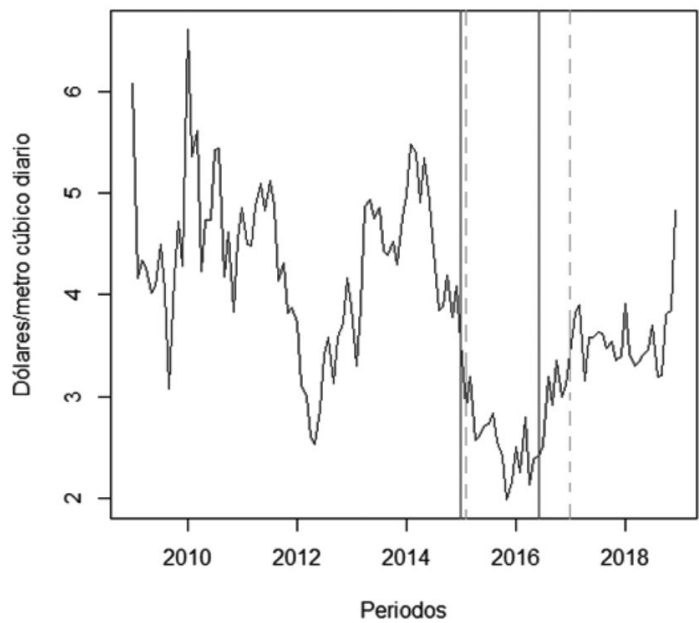

Figura 2(e). Puntos de cambios estructurales en la serie de gas natural utilizado en generación de electricidad

Precios del gas natural

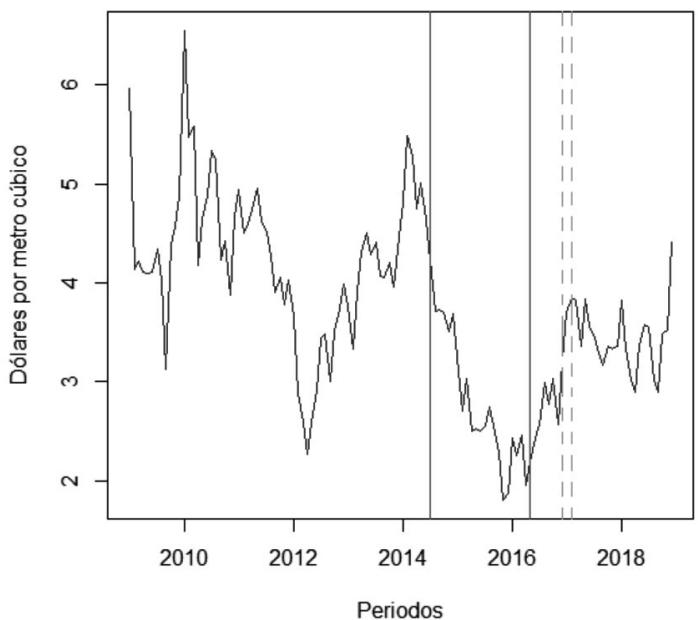

Figura 2(f). Puntos de cambios estructurales en la serie de precios totales de gas natural. 


\section{Conclusiones}

En este artículo analizamos los efectos de la reforma regulatoria del mercado de gas natural, iniciada en 1995 y culminada en 2013, sobre el comportamiento de sus precios, ventas y comercio exterior. Aun cuando esta reforma es parte de un proceso, los cambios en 1995 difieren en naturaleza de los registrados en 2015. Mientras que la reforma de 1995 mantuvo el monopolio de PEMEX a la par que permitió la participación de agentes privados en proyectos de distribución y desarrollo de redes de gasoductos a lo largo de diversas ciudades del país, la reforma de 2013 profundizó sustancialmente la liberalización institucional del sector de gas natural. De hecho, la última reforma es la de mayor envergadura porque no solo abarcó a las industrias del petróleo crudo, petrolíferos y electricidad, sino que también logró, al menos formalmente, la desintegración vertical de PEMEX y CFE. Además, esta reforma favoreció la celebración de contratos y alianzas con empresas privadas nacionales y extranjeras y creó o consolidó diversas agencias reguladoras para proveer de un marco regulatorio estable y creíble a las empresas inversoras.

La conclusión principal de este artículo es que la aplicación de las pruebas estadísticas sustenta la existencia de quiebres en intercepto y tendencia que modifican la dirección de las trayectorias de todas las series entre 2016 y 2017. Como se sabe, la prueba de quiebre estructural de Zivot-Andrews aquí utilizada, detecta el quiebre más importante del periodo, pero no los de menor rango. De ahí que el documento no explica (porque ese no es su objetivo) los cambios previos o posteriores a ese quiebre. Por eso es probable que el análisis estadístico aquí desarrollado omita algunos comportamientos de las series que presenten estacionariedad y reversión a la media, como los descritos en la Tabla 1. Así que una línea futura de investigación bastante fructífera sería, sin duda, el estudio de estas series para periodos previos o posteriores a los grandes quiebres que permitan detectar comportamientos diferentes a los de raíz unitaria.

Los principales eventos de la industria del gas natural en México asociados con estos cambios de tendencia durante 2016-2017 tienen que ver con el incremento de la capacidad de transporte de la red nacional de gasoductos posterior a la puesta en marcha de Los Ramones II (tramos norte y sur, con longitud de 738 km) en 2016, y de San-Isidro-Samalayuca, El Oro-Mazatlán, Ojinaga-El Encino, Guaymas-El Oro (con longitud de 1,006 km) en 2017. Esta nueva capacidad de ductos, aunado a los nuevos gasoductos de internación (Trans-Pecos Pipeline, Comanche-Trail Pipeline) introducidos también en 2017, significó la adición 
de 2,272 km a la red de transporte. ${ }^{20}$ Esto es, durante el periodo 2016-2017 se añadieron más del 50\% de la capacidad nueva de transporte de gas entre 20012 y 2019. Así mismo es importante notar que en estos años se inició la operación del gasoducto de Los Ramones al centro del país: un punto de arbitraje nodal del sistema que es crítico para la determinación de los precios y volúmenes del gas natural en todo el país. (Brito y Rosellón, 2002, 2005, 2010)

Adicionalmente, el cambio estructural registrado en los volúmenes de importación del gas natural durante el año de 2016 es muy significativo para evaluar el desempeño de la reforma energética $\mathrm{y}$, en particular, para ponderar las posibilidades reales de la disminución de la dependencia externa de ese producto clave. Este último aspecto es de la mayor importancia, porque no hay que olvidar que la mitad del consumo energético y dos terceras partes de la electricidad del país son suministrados por ese combustible. Además, hay que considerar que, ante la baja de las ventas de petróleo a EEUU, el déficit comercial en petróleo, gasolinas diésel y gas natural ha estado aumentando considerablemente hasta alcanzar 12,500 millones de dólares en 2017 o, si consideramos los petroquímicos, sube a 23,000 millones de dólares en 2018 (Ramírez y Massa 2020). Obviamente la reforma energética es un proceso en ciernes y todavía tendría que valorarse si este cambio estructural es capaz de romper el patrón comercial montado en los últimos años de operación del NAFTA, consistente en exportar cada vez menos crudo e importar cada vez más productos petroleros refinados de EEUU.

El documento aporta además evidencia estadística del impacto permanente que las reformas del gas natural en México han tenido sobre el valor del comercio exterior de este hidrocarburo. ¿Cuáles podrían ser las implicaciones de política pública de este hallazgo? Una primera interpretación sería que las reformas de apertura del mercado han implicado una dependencia en México cada vez mayor del gas natural de lutita (shale gas) de los EEUU debido a una lógica económica basada en liberalización, competencia y minimización de costos. Esto es, importar shale gas de EEUU sería una solución económicamente eficiente para satisfacer la creciente demanda del gas natural en México, en particular la vinculada al desarrollo de la generación eléctrica de ciclo combinado. Las reformas deberían entonces mantenerse en pie y dejarlas evolucionar hasta lograr los efectos económicos positivos esperados, en particular sobre los precios del gas. Asimismo, esta lógica de política pública coincidiría con minimizar los costos ambientales del fracking del gas en México, que recaerían mayormente en la industria del gas natural de Texas. Sin embargo, una desventaja sería la alta dependencia del sistema eléctrico mexicano en un insumo energético importado. ¿Sería, entonces, esto último una razón suficiente para revertir la lógica de apertura de las reformas al sector y, en

$\overline{{ }^{20} \text { Ver Sener }}$ (2019) 
consecuencia, aceptar la existencia de un monopolio nacional verticalmente integrado en la producción de gas natural? Dicha política pública en realidad no sería minimizadora de costos (ni amigable al medio ambiente), principalmente si no se fundamentara en procesos de fracking en México regulados adecuadamente. Como se argumenta en Sarmiento et al. (2019), una política tal vez más sensata --que armoniza soberanía energética con eficiencia económica y ambiental en nuestro país-- podría fundamentarse en una descarbonización acelerada con energía renovable solar y eólica (Mexican Green New Deal).

\section{Referencias}

Andrews, D., (1993). 'Tests for parametric instability and structural change with unknown change point', Econometrica 61(4): 821-856. https://doi.org/10.2307/2951764

Andrews, Donald (2003). "Tests for parameter instability and structural change with unknown change point: A Corrigendum”. Econometrica. 71 (1): 395-397. DOI: https://doi.org/10.1111/1468-0262.00405

BP Statistical Review of World Energy 2019. British Petroleum, 2019, pp. 9.

Brito D.L. and J. Rosellón (2010), "Pricing Natural Gas in Mexico: An Application of the Little-Mirrlees Rule The Case of Quasi-Rents", Southern Economic Journal, Southern Economic Association, vol. 76(4), pages 1131-1136, April. DOI: https://doi.org/10.2307/27866747

Brito D.L. and J. Rosellón (2005), "Price Regulation in a Vertically Integrated Natural Gas Industry: The Case of Mexico", Review of Network Economics, De Gruyter, vol. 4(1), pages 1-18, March. DOI: https://doi. org/10.2202/1446-9022.1067

Brito, D. L., and J. Rosellón, (2002), "Pricing Natural Gas: An Application of the Little-Mirrlees Rule", Energy Journal, vol. 23, no. 3, pp. 81-93. https://doi.org/10.5547/issn0195-6574-ej-vol23-no3-4

Cheung, Y.W., and Lai, K.S., (2000), "On cross-country differences in the persistence of real exchange rates", Journal of International Economics, vol. 50 (2000), pp. 375-397. DOI: https://doi.org/10.1016/S00221996(98)00079-8

Franco, G. (2019). "Reservas de hidrocarburos en México. Conceptos fundamentales y análisis 2018”, Comisión Nacional de Hidrocarburos, México, 2019.

Halpern, J. and Rosellón, J. (2001), "Regulatory Reform in Mexico's Natural Gas Industry: Liberalization in the Context of a Dominant Upstream Incumbent", Policy Research Working Paper Series, 2537. The World Bank. https://doi.org/10.1596/1813-9450-2537

Hu, H. Wei, W. and Chang, C., (2019). "Do shale gas and oil productions move in convergence? An investigation using unit roots with structural breaks". Economic Modeling, Vol.77 pp 21-33. https://doi.org/10.1016/j.econ$\bmod 2018.12 .006$

Kwiatkowski, D.; Phillips, P. C. B.; Schmidt, P.; Shin, Y. (1992). "Testing the null hypothesis of stationarity against the alternative of a unit root". Journal of Econometrics. 54 (1-3): 159-178. https://doi.org/10.1016/03044076(92)90104-y

Maddala, G., y Kim, In-Moo (1998). Unit roots, cointegration and structural change. Cambridge University Press.

Pérez, D. y Zubicaray, G. (2017), "El impacto urbano de la Reforma Energética en las ciudades del Golfo de México”, Working paper. World Resources Institute. Septiembre 2017, pág. 6.

Perron, P. (1990). "Testing for a Unit Root in a Time Series with a Changing Mean", Journal of Business and Economic Statistics, Vol 8. 
Ramírez, J.C and R. Massa, (2020). Mexico's energy reform in the context of a new trilateral agreement (T-MEC-USMCA). International Trade Journal, Vol 34 (1) pp. 55-73. https://doi.org/10.1080/08853908.2 019.1693939

Ramírez, J.C. and J. Rosellón, (2002), "Pricing Natural Gas Distribution in México", Energy Economics, 24(3), 231-248. https://doi.org/10.1016/s0140-9883(02)00037-3

Rogozinski, J. (1999). High Price for Change: Privatization in Mexico, The Inter-American Development Bank and the Johns Hopkins University Press, 1999. https://doi.org/10.5465/ame.1999.2210322

Rosellón, J. (1998). "Price and Rate Regulations for the Mexican Natural Gas Industry: Comments on Policy Decisions", Economía Mexicana, vol. VII, núm. 2, CIDE.

Russo, T. (2017). Will NAFTA renegotiation stop greening of Mexico's power sector? Natural gas \& Electricity. volume 34 issue 2, pp. 30-32. https://doi.org/10.1002/gas.22006

Sarmiento, L., T. Burandt, K. Löffler, P-Y, Oei (2019), “Analyzing Scenarios for the Integration of Renewable Energy Sources in the Mexican Energy System-An Application of the Global Energy System Model (GENeSYS-MOD)", Energies, 12(17), 3270; https://doi.org/10.3390/en12173270

SENER (2019). Estatus de infraestructura de gas natural. Octubre 2019. Secretaría de Energía, México.

https://www.gob.mx/cms/uploads/attachment/file/497827/Estatus_de_gasoductos_octubre_2019.pdf consultado el 9 de junio de 2020. 